CRÍTICA, Revista Hispanoamericana de Filosofia

Vol. XXI, No. 63 (diciembre 1989): 59-73

\title{
WHAT DO LANGUAGE GAMES MEASURE?
}

KUNO LORENZ

Universidad de Saarbrücken

Saarlandes, R. F. A.

In order to understand the function of language games it is very useful to look somewhat more closely into one of the most important metaphors Wittgenstein has used throughout his life. My main concern will be an explication of how the term 'Bild' (picture) has changed its meaning when going from the Tractatus (T) to the Philosophical Investigations (PU) by determining precisely that function of 'Bild' which has been kept constant. Let me start with the well-known fact that 'Bild' is something on the level of sentences both in the T and in the PU: In his Notebooks (29.9.14) Wittgenstein writes: "In the sentence a world is put together experimentally. (As when in the law-court in Paris a motor-car accident is represented by means of dolls, etc.") And in the T he continues (4.0311f): "One name stands for one thing, and another for another thing, and they are connected together. And so the whole, like a living picture, presentes the state of affairs. The possibility of sentences is based upon the principle of the substitution (Vertretung) of objects by signs". Quite alike we read in the PU ( $(23)$ : "Imagine a picture representing a boxer in a particular stance. Now, this picture can be used to tell someone how he should stand, should hold himself; or how he should not hold himself; or how a particular man did stand in such-and-such a place; and so on. One might $[\ldots]$ call this picture a sentence-radical. "Of course, there is 
a slight but significant change we should at once try to note. In the T-quotation, the picture represents a state of affairs as is the case with sentences, whereas in the PU-quotation, the picture can be used, e. g., to represent a state of affairs, but also for other purposes, as is the case with sentence-radicals which, when they are used, are complemented by their modes yielding assertions, questions, commands, etc. So it looks, and speech-act-theory usually proceeds that way as if there is a basic locutionary act, 'predication', executed by 'propositional kernels', which in utterances, $i$. $e$., in sentences in use, appears as locutionary meaning together with illocutionary and perlocutionary force. Wittgenstein is said to have treated in his $\mathrm{T}$, locutionary meaning only and to have given up this notion in favour of a study of speech-acts with predications, within this context better to be called: constatations or assertions, being just one among them.

Hence, rather than dealing with one language-game saying something about objects as a function of their names - as Wittgenstein is said to have done in the $\mathrm{T}$ the arena is open for the study of an unlimited variety of such games, - that is Wittgenstein's opinion - which speech-act-theorists claim to be able to boil down to essentially five types.

I think that such an account is a distortion of Wittgenstein's ideas. It came about presumably because the change of meaning of some crucial terms, implied by the change from a level of explanation to a level of description which took place according to Wittgenstein's own words between the $\mathrm{T}$ and the $\mathrm{PU}$, went by more or less unnoticed. I am referring not only to the term 'Bild' but also to the term 'Satz', both of which keep their relation to each other almost unchanged - you remember: whereas a picture is like a sentence in the $\mathrm{T}$, it is like a sentence-radical in the PU-, but they are moved to another level. Using a Peircean terminology I claim that the picture (as well as a sentence) functions as a symbolic representation in the $\mathrm{T}$ but it functions - together with sentence-radicals - as 
a means of iconic representations in the PU. This implies that language-games are Wittgenstein's version of iconic representations, and that the term 'language-game' cannot properly be applied to the picture-theory of the $\mathrm{T}$.

In order to corroborate my claim I first want to sketch what I have argued for elsewhere in detail: Sentences in the T represent a state of affairs by being representatives of an abstractionclass with respect to the equivalence relation among sentences which is expressed by rules of translation. Rendering the picture-theory of the $\mathrm{T}$ in such a way as a theory of abstraction obviously entails the assertion that pictures in the $T$ are symbolic representations. Now the reasons: Starting-point is the wellknown passage in his Notebook (27.10.14): "The difficulty of my theory of logical portrayal was that of finding a connexion between the signs on paper and a situation outside in the world. I always said that truth is a relation between the proposition and the situation, but could never pick out such a relation". Even more general two months earlier (3.9.14) he declares: "The obscurity obviously resides in the question: what does the logical identity of sign and things signified really consist in? And this question is (once more) a main aspect of the whole philosophical problem". You all know that by the time of actually writing the $T$, the logical identity of sign and thing signified has become an internal relation which shows itself and which cannot be said, whereas the relation between proposition and situation he was looking for in vain is an external relation which indeed does not exist. Here, already, we have tracked down the germ of one of the most basic insides which, even now has not been fully recognized by everybody working in that area: it is Wittgenstein's realization that the copula, relating a sign and one or more objects to get a predication, is not an ordinary relation between objects; it rather is the means in order to be able to state that such an ordinary relation holds.

The distinction of 'internal' and 'external', which is used more or less synonymously with the traditional distinction of 
'formal' and 'material' is turned into a tool; the tool is used to give a clear account of what it means to stay on the object-level (to treat objects, properties, relations, all external ones) and what it means to exhibit the very means necessary to make objects, properties, etc. available. These means are internally related to objects, etc.; they are purely semiotic tools or 'symbols' which must not be confounded with the material carriers of symbols, $e$. g., sounds, which receive their function by convention, that is an external relation.

From a number of relevant passages in the $\mathrm{T}(4.124,2.0123$, $2.01231,2.0141$ ) you may derive: (1) to know an object is equivalent to know all of its internal properties, (2) to know an object is equivalent to know all the possibilities of its occurrence in state of affairs, (3) forms of an object are possibilities of its occurrence in state of affairs. These three sentences imply: internal properties of an object are its forms, $i$. e., its formal properties. And these forms of objects determine completely the structures of those states of affairs in which they can occur. There are no external properties of state of affairs (thus explaining why they have to be kept distinct from objects).

Let us turn to the central passage in the $\mathrm{T}$ (4.01) where Wittgenstein gives an account of the internal relation between language and the world, a passage which is usually taken to prove the thesis of an isomorphism between language and the world. But certainly isomorphisms are special external relations between objects. I quote: "The sentence [as sentences are sentence-signs, physical object-types and not tokens, together with their function of signification, hence are symbols, they are usually rendered in English as propositions which, though approved by Wittgenstein, unfortunately invites the reader to turn to the superfluous discussion about the ontological status of these entities] is a picture of reality. The sentence is a model of reality as we think it is. At the first glance the sentence - say as it stands printed on paper- does not seem to be a picture of the reality of which it treats. But nor does the musical score 
at first sight to be a picture of a musical piece [...] And yet these symbolisms prove to be pictures - in the ordinary sense of the word - of what they represent [...] the grammophone record, the musical thought, the score, the waves of sound, all stand to one another in that pictorial internal relation which holds between language and the world. To all of them the logical structure is common".

Let me insert that 'logical structure' a term which does not occur elsewhere in the T has to be read as 'logical form of representation' ( $=$ form of reality); different equivalent pictures have different forms of representation, but are alike in their logical form. The passage continues by referring to rules of translation between different pictures establishing their equivalence - 'internal similarity' Wittgenstein says - and it ends with the following words: "In order to understand the essence of the sentence, consider hieroglyphic writing which pictures the facts it describes". We have now to add that "The holding of such internal properties and relations cannot, however, be asserted by sentences but it shows itself in the sentences which represent the states of affairs and treat of the objects in question" (4.122). Hence, the internal relation between language and the world shows itself in the sentences and cannot be turned into the cbject of metasentences. In fact, as we have learned from Moore's lecture notes (1930-33), Wittgenstein considers internal relations to be grammatical ones, his term for what we would call today 'semiotic relations'. Wittgenstein himself gives reasons for his use of the term 'Bild' for the internal relation between a sentence and a state of affairs: he refers to the fact that a sentence is understood solely on the basis of our knowledge of the objects about which the sentence says something; and here 'knowledge' is knowing the internal properties, i. e., the ones by which the objects are 'defined'. A picture can be true or false, that is why it is called a model of reality (2.1512): "it is like a measuring-rod applied to reality". Here, too, the corresponding idea concerning language-games suggests itself: in the PU 
$\S \tilde{1} 30 \mathrm{f}$ Wittgenstein declares that "language-games are rather set up as objects of comparison which are meant to throw light on the facts of our language by way not only of similarities but also of dissimilarities. For we can avoid ineptness or emptiness of our assertions only by presenting the model as what it is, as an object of comparison as, so to speak, a measuring-rod". And, again, the slight, though decisive difference: in the T-case sentences being measuring-rods are carriers of truth-values, in the PU-case language-games being measuring-rods tell you what there is. We have moved from an epistemological level to an ontological level.

Let us return a last time to the argumentation in the T: We already know that sentences being means to say something about objects (i. e., to describe/to represent states of affairs) are not names of anything, but -as Wittgenstein writes in his Notebooks (21.11.14) - "the realities corresponding to the sense of a sentence are only its component parts", hence the objects about which you say something stand on the other side of language, not the states of affairs; what you say about them, that a state of affairs holds, $i$. e., that it is a fact, belongs to language alone. This is the root of the distinction between the world (the totality of reality) and substance of the world.

Now, sentences have essential features, $i$. e., internal properties which are common to all sentence-signs expressing the same sense. And for all symbols, whether names or sentences, Wittgenstein notes that "what signifies in the symbol is what is common to all those symbols by which it can be replaced according to the rules of logical syntax" (3.344). We have again arrived at the rules of translation which eventually define what it means to have the same sense: "In order to recognize the symbol in the sign we must consider the significant use. The sign determines a logical form only together with its logical syntactic application" (3.326f).

The ideal language postulated by Wittgenstein in the $T$ should be considered as a comprehensive language with every 
well-established symbolic language belonging to it. Then, the rules of translation are part of the logical syntax of the ideal language and can be used as an equivalence-relation to define states of affairs by abstraction. Every kind of meaning can actually be defined in that manner. And Wittgenstein has indeed succeeded in eliminating every reference to meaning in setting up the rules of logical syntax (3.33): "In logical syntax the meaning of a sign ought never to play a role; it must admit of being established without mention being thereby made of the meaning of a sign". Hence, "The rules of logical syntax must follow of themselves, if we only know how every single sign signifies" (3.334).

We may conclude: the sense of sentences is fully explained by the use you make of them, i. e., by the syntactic rules, provided we know what shows itself when using a sentence. And it is this knowledge of what shows itself, when using sentences, which becomes Wittgenstein's concern in the PU. The language-games serve as a kind of 'rational reconstruction' in order to show (providing active knowledge) what shows itself (passive knowledge) in the T. When Wittgenstein says, as I have quoted already, that language-games are a measuring-rod for the facts of our language, it is not preexisting 'facts' (German: Verhältnisse) which are brought into focus by them. They rather provide 'perspicuous representations' $(\S 122)$-a term very near in fact to my claim of language-games being iconic representations - which Wittgenstein is calling fundamental thus stressing the semiotic feature of language-games beside their obvious pragmatic character.

Rather than being means to speak about objects languagegames show what kind of objects you are dealing with and in vihich manner. They articulate situations by exposing their function among persons. A language-game is both a world view and a way of life. This idea coincides with an insight which we find in Plato already when, in his Cratylos, he speaks of the two main characteristics of human speech, its significative function 
and its communicative function. In fact, each utterance shows two features, it signifies and it communicates, that is, it plays the role of a term (or a word) and the role of a sentence, well known in the simplest case of one-word-sentences as in the famous samples of language-games in the opening sections of the PU, where the expressions 'block', 'pillar', 'slab', and so on, serve both functions.

Language-games are a kind of activity which aims at disclosure of what is going on by providing tools of comparison. You not only observe and describe actions and sign-actions thereby according to certain standards but you also produce them in an orderly fashion - perspicuously, as we have noted already - in onder to arrive at some kind of approximating reconstruction of what you take to be available, already. A language-game may count as a paradigm case of perceptual knowledge insofar as its significative function works by being an icon in the sense of C. S. Peirce: you have found an area of internally structured objects by inventing a prototype. And it becomes obvious that even the distinction of action and sign-action, a special case of the basic and embarrassing distinction between the world and language, has to be relativized in view of a purely functional account of what it means to be an object and what it means to be a sign of an object.

We have to try, therefore, to develop a unified approach to both objects and signs of objects quite in line with the pragmatic methodology of Peirce that a theory of designation and a theory of designata has to be a combined endeavour. My suggestion is to turn to a dialogue-model where you start with a situation of acquiring both an action-competence and a signaction-competence. As a preparatory step I ask you to look at verbal language or other symbol systems in use primarily as types of actions like eating or sleeping with the consequence that in this respect they themselves are parts of the objects they refer to, and complementarily to look at the non-linguistic, especially non-symbolic, objects as parts in a web of interrelated 
and interdependant actions, thus taking into account that they partake in the significative value of the activities they are embedded in.

Hence, what we do initially is to naturalize language including other symbol systems and to symbolize world by paying attention to that feature of actions which appears in the focus when we recognize actions rather than just perform them. The bridge over the apparent gap between the world and language can be built if you make that gap disappear. Actions are both performed - the natural or empirical aspect of actions- and understood - the symbolic or rational aspect of actions-; from the first perspective you produce tokens of a type, and from the second perspective you 'identify' different tokens as belonging to the same type.

We will proceed now in a more systematic fashion and actually set up our dialogue-model in order to get a firmer grasp of the two fundamental aspects of actions, the performance-aspect and the recognition-aspect which we will now call the pragmatic and the semiotic aspect, respectively. It is not at all a new insight, I should add, that with every action the distinction of mere acting and of acting as a kind of language is applicable, though this feature-splitting has not been used yet for a genetic reconstruction of linguistic competence, of some initial stages of linguistic competence at least, from processes of acquiring action-schemata (= action types).

The dialogue-model consists in an elementary situation of two persons being engaged in starting and continuing a process of acquiring competence to perform a certain action. The twoperson elementary situation is nothing but a generalized and more elementary version of a Wittgensteinian language-game, especially with respect to its role to function as a measuring-rod (PU $\S 131$ ) for already occurring complexes of actions including linguistic ones. To start with processes of action-acquisition rather than with either sets of action-events (some kind of exterior singular entities) or sets of pragmatic competences (some 
kind of interior universal entities) derives from the necessity to avoid the ever-present pitfalls of Cartesian dualism with its awkward consequence to use either a behavioristic or a mentalistic approach to account for our abilities, in particular our linguistic ones. It is the purpose of the elementary dialoguesituations together with the construction of a gradually growing differentiation into more and more complex dialogue-situations to keep a unified account of how we acquire both participation in a common situation and use of a common piece of language. It comes about by looking carefully at the two points of view exercised by the two agents in such a situation of competence acquisition. At a given time one of them is performing and the other one recognizing the action, and in the course of the acquisition processes the points of view switch permanently. By way of caution, I should add that the two terms 'performing' and 'recognizing' are applicable only post hoc, i. e., after the open sequence of switching roles has taken place and both agents have acquired the competence in question.

The primary objects available with any such competence are actions without any further differentiation as yet, neither with respect to act and agent, nor with respect to act and object of an act, nor otherwise. But all of them both are and are known to be common in the respective situation, even better: each one of them is a common situation and both parties know it. Again you may think of the famous rabbit-situation in Wittgenstein's PU (II:XI), where in the course of discussing 'seeing something' and 'seeing as' he gives the example of an exclamation 'A rabbit!' whereby a landscape with a running rabbit turns into a rabbit-situation; this "flashing of an aspect" he describes as "half visual experience, half thought". Of course, we have here a more advanced dialogue-situation insofar as the speaker is exclaiming 'A rabbit!' incorporates both parties of our elementary situation with some significant further developments: as performing party the speaker performs a perceptual action, as recognizing party he utters 'A rabbit!', and acquisi- 
tion of 'rabbit-competence' is a sudden one-step affair. In the report-case 'A rabbit' on the other hand you rely on an already perceptually defined situation, e.g., you remember rabbits from previous occasions.

In order to keep the different stages in the development of our dialogue-model distinct it is better to call the elementary and rather primitive though common world to consist of preactions. Neither things nor persons, nor rabbits in the usual sense belong to them; looking backward from a later stage you may say that things, persons, animals, etc., are as yet indistinguishable parts of preactions. And it is important to be conscious of the fact that preactions have neither the status of given data nor of rational constructions as the traditional alternative in terms of the empiricism-rationalism-debate on the primary level of reality would ask us to decide between and which also Wittgenstein wanted to avoid. Preactions are performed by the acting agent and recognized by the other party, that's all.

Realizing now that the performance viewpoint is pragmatic, whereas the recognition viewpoint is semiotic, we may say that our model of elementary dialogue-interaction permits us to distinguish a pragmatic and a semiotic aspect with every preaction. You get a concrete version of the sign-character of a preaction if you look at the non-performing party during a particular instant of the dialogue-situation as someone who understands the performance of the other party, e. g., as an invitation to do 'the same'.

We take a further step now by turning the recognition viewpoint of a preaction into an explicit preaction of its own. What is going to happen: instead of simply recognizing smoking, for example, you perform a separate preaction, say see-smoking, which qualifies as a perception with respect to the original preaction. To recognize a preaction is to perform a perception of a preaction. Therefore, in the elementary dialogue-situation the person who performs smoking is at the same time recognizing the perception of his partner, that is, in more colloquial terms, 
he knows that the one who perceives does himself know what is smoking through performing a perceptual preaction with respect to smoking, or: he knows that his partner is knowing how to smoke.

The next step of identifying the recognition aspect of a preaction with the performance aspect of a perception of the preaction which may be called 'objectivation' leads to the stage of object constitution independent from particular dialoguesituations. By pragmatic abstraction, as we may say, we define a preobject -I don't use the term 'object' because there will be no division into individual units, the individuals, as yetas the invariant out of the open set of relevant perceptions irrespective of the particular dialogic acquisition-process of the original preaction.

To recognize a preobject is nothing but performing a corresponding perception; preobjects themselves cannot any more be performed, they are the same for all participants though with different perceptual access. Even actions as preobjects are not performed, what you perform, for example, in the case of smoking as a preobject, is smoking as showing-smoking, that is, you are presenting (in German: vorführen) smoking. Only by presenting actions they count, like things, persons, events, etc. - though we did not yet develop criteria of classifying preobjects into kinds-, as preobjects and not merely as preactions.

We call preobjects articulated by their perceptions. But it is a contingent anthropological fact that certain perceptual preactions out of the manifold of articulations of a preobject, namely verbal preactions, receive canonical status with respect to their being a sign of the preobject: as a kind of symptom they represent the preobject 'pars pro toto'. For the next step of turning the verbal preactions into preobjects of their own without thereby cutting off their perceptual, $i$. e., semiotic function, we return to dialogue-situations of second order. Such dialoguesituations serve as genetic reconstructions of what in the tradition of philosophical logic has been called (situations of) "pred- 
ication'. The verbal preobjects or rather their spoken or written results made available by pragmatic abstraction with the help of such second order dialogue-situations I call articulators and we know already that they cannot be performed in the strict sense but only presented. To utter an articulator, or to perform an articulation or a predication, say 'smoking' - which is the 'verbal perception' of the preobject smoking - is at the same time a case of recognizing it. An articulator is, as a preobject, a fullfledged symbolic sign, and not any more a mere symptomatic one. We may distinguish these two semiotic functions of an articulator by saying: in its symptomatic function an articulator is constitutive of its object, in its symbolic function it describes its object. Obviously, also pictures can be used as articulators.

Only now we have reached the stage where articulations being both signs and actions, that is sign-actions, or better: semiotic actions, can be subjected to the two aspects which I referred to as the two basic functions of language: the function of signification and the function of communication. To avoid confusion it is advisable to use the term 'articulation' only with respect to its significative function, and to switch to the term 'predication' when the communicative function of articulation is of concern. Since it generally holds that with respect to its pragmatic character a sign-action is communicative, and with respect to its semiotic character an action is significative, we can say that an articulation in its significative aspect is realized by performing a perception. Hence, the 'meaning' of an articulator splits into the different perspectives of the persons using the articulator and, thus only, common meanings can be ensured. Likewise, an articulation, in its communicative aspect, that is a predication as an action, splits into two different ways of being given -again the result of an objectivation, here of second order, by turning the recognition of a predication into an independent action, which is called a mode of the predication. The more familiar term nowadays for such a 
mode is, of course, 'speech act'. Predications always occur in a mode, the speech act between speaker and hearer: the secondorder dialogue-situations appear as the systematic equivalents to Wittgenstein's language games in the strict sense.

And what has become clear, I hope, is that language-use always occurs on two levels: as a perception, that is as a way of presenting an object - the rabbit-exclamation, a case of objectcompetence- - and as a conception, that is as a way of referring back to other terms used already perceptually — the rabbitreport, a case of metacompetence.

In the $\mathrm{T}$ Wittgenstein is treating the ability to use sentences and pictures generally as a case of metacompetence with respect to sign-actions, whereas in the PU he is presenting language-games and the use of pictures as a case of object-competence with respect to sign-actions. In this latter case they serve as exemplifying sign-actions using a terminology of Goodman. If, as a piece of rethoric, you disregard the equivocation thus connected with the term 'Bild', you may say and I want to conclude my talk in that manner: In the $\mathrm{T}$ pictures are symbols, whereas in the PU language-games are pictures in use.

Recibido: 31 agosto 1989. 


\section{RESUMEN}

Tomando como punto de partida los parágrafos 130 y 131 de las Investigaciones filosóficas, en los que un juego-de-lenguaje recibe el nombre de 'objeto de comparación' o 'regla de medición' para los hechos de nuestro lenguaje, se argumenta que los 'hechos' preexistentes (en alemán, Verhältnisse) no son los que los juegos-de-lenguaje ponen de relieve. Sirven más bien como una especie ċe 'reconstrucción racional' (el término de Wittgenstein es 'representación perspicua', $§ 122$, término que él considera fundamental y que está subrayando el aspecto semiótico de los juegos-delenguaje, probablemente porque su aspecto pragmático es obvio) para saber qué estamos haciendo. Por lo tanto, su carácter semiótico es icónico (y no simbólico como lo era el nivel de lenguaje del Tractatus) en el sentido de Peirce y debe ponerse en relación con la ejemplificación desarrollada en la teoría de los símbolos de N. Goodman. Finalmente, se analiza en qué sentido coinciden con los cambios-en-los-hábitos de Pierce o difieren de ellos, siendo éstos los intérpretes lógicos últimos de los signos.

$[K . L$. 